\title{
CONFLITOS COM O "LÁPIS COR DE PELE": A SÉRIE POLVO, DE ADRIANA VAREJÃO E O MULTICULTURALISMO NO ENSINO DE ARTE
}

\author{
João Paulo Baliscei ${ }^{1}$ \\ Geiva Carolina Calsa ${ }^{2}$ \\ Ana Caroline Marques Godinho ${ }^{3}$
}

\begin{abstract}
Resumo
Baseado em experiências vivenciadas com os alunos e alunas do $3^{\circ}$ ano do Ensino Fundamental de uma escola pública de Maringá, Paraná, esse artigo tem por objetivo problematizar o papel do/a professor/a de arte enquanto mediador/a na formação multicultural do sujeito contemporâneo. A partir das discussões a respeito dos estereótipos de cor, procuramos pensar em possíveis estratégias pedagógicas para questionar o uso do "lápis cor de pele" e desenvolver reflexões sobre a naturalidade com que é eleito para pintar desenhos, como se o uso de outra cor fosse "proibido". Seria esse lápis o único possível para o preenchimento e caracterização da pele? Para discutir sobre esses aspectos, abordamos a série Polvo, da artista Adriana Varejão, o multiculturalismo e práticas de ensino de Arte. Consideramos que questionar estereótipos em sala de aula proporciona aos/às alunos/as reflexões que podem modificar seus olhares e comportamentos frente às diferenças.
\end{abstract}

Palavras-chave: Educação; Estereótipo; Infância; Visualidades; Cultura

\section{TRABALHANDO AS CORES EM SALA DE AULA}

"Eu tinha 9 anos quando Star Trek foi ao ar. Eu olhei para a tela e saí correndo pela casa, gritando:

'Vem aqui, mãe, gente, depressa, vem logo!

\footnotetext{
1 Doutorando em Educação pela Programa de Pós-Graduação da Universidade Estadual de Maringá (UEM), professor lotado no Departamento de Teoria e Prática da Educação da UEM. Endereço: Av. Colombo, 5.790. Jd. Universitário, Maringá - Paraná - Brasil, CEP 87020-900. E-mail: vjbaliste@ gmail.com.

2 Doutora em Educação pelo Programa de Pós-Graduação da Universidade Estadual de Campinas, professora adjunta lotada no Departamento de Teoria e Prática da Educação da UEM. Endereço: Av. Colombo, 5.790. Jd. Universitário, Maringá - Paraná - Brasil, CEP 87020-900. E-mail: gccalsa@ gmail.com.

${ }^{3}$ Graduada em Artes Visuais pela UEM. Endereço: Av. Colombo, 5.790. Jd.Universitário, Maringá - Paraná Brasil, CEP 87020-900. E-mail: cacaro193@ hotmail.com
} 
Tem uma moça negra na televisão e ela não é empregada!'. Naquele momento eu soube que podia ser o que eu quisesse".

(Whoopi Goldberg)

Durante as observações e as regências feitas na disciplina de Estágio Supervisionado em Artes Visuais ${ }^{4}$, no curso de Artes Visuais da Universidade Estadual de Maringá, Paraná, no ano de 2014, tomamos a decisão de aprofundar nossas pesquisas sobre arte e educação. Vislumbramos no Estágio Curricular oportunidades para que os/as formandos/as pensem e problematizem suas identidades docentes, assim como para que desenvolvam características próprias da pesquisa em Educação, como a curiosidade, o questionamento, a insatisfação com o já sabido e a preocupação com o currículo, recurso didático e disposição do espaço escolar.

Oliveira (2005) aponta que no exercício do Estágio Curricular o/a estudante de licenciatura precisa ser orientado/a a enxergar tal atividade como um campo de pesquisa, aplicação e execução daquilo que até então era apresentado, discutido e investigado de maneira teórica, por meio de conceitos explorados em outros momentos e disciplinas da graduação.

O estágio curricular é a disciplina que permite aos alunos de licenciatura a apropriação de instrumentos teórico-metodológicos para a atuação no ambiente escolar. De posse do conhecimento específico (saber disciplinar) agora é o momento deste aluno tentar compreender as políticas educacionais, a escola e o próprio sistema de ensino. Este é o momento da formação que objetiva preparar o estagiário para levar sua proposta de prática educativa - o projeto de estágio, a este novo ambiente. (OLIVEIRA, 2005, p.60)

Durante as observações e intervenções pedagógicas que realizamos junto aos alunos e alunas do $3^{\circ}$ ano do Ensino Fundamental, na disciplina de Arte, avaliamos que suas práticas artísticas apresentaram características "pouco flexíveis" no que tange às maneiras de pintar e às escolhas de cores. Em seus desenhos, frequentemente as personagens - pessoas, animais, objetos- eram pintadas com cabelos amarelados e com a pele clara. Para pintar os espaços equivalentes à pele, os meninos e meninas faziam uso do lápis convencionalmente chamado de "cor de pele" - tonalidade esta semelhante ao rosa claro, salmão ou coral. Pudemos notar inclusive, que mesmo aqueles alunos e alunas cujo tom da pele era mais escuro e os cabelos eram castanhos ou negros optavam por pintar as pessoas com o lápis rosa claro e os cabelos

\footnotetext{
${ }^{4}$ As vivências com o Estágio Supervisionado em Artes Visuais ocorrem a partir do quarto semestre do curso de Artes Visuais, da Universidade Estadual de Maringá. Um de seus objetivos é elaborar e executar projetos na escola que favoreçam a percepção estética e a ampliação do repertorio artístico (UEM, 2010).

${ }^{5}$ Nesse artigo, utilizamos os termos "lápis cor de pele" entre aspas, primeiramente, para fazer referência às falas dos indivíduos escolares e, em segundo, para marcar nossa insatisfação e discordância por essa nomeação.
} 
BALISCEI, J. P.; CALSA, G. C.; GODINHO, A. C. M.

com o lápis amarelo, fazendo alusão, de certa forma, ao ideal de beleza que é reproduzido nas e pelas imagens da cultura popular. Souza, Baliscei e Teruya (2015) apontam as imagens acessíveis e populares entre os/as jovens e crianças, tais como as televisivas, cinematográficas e publicitárias, oferecem representações específicas e excludentes. O autor e as autoras analisaram vitrines de 65 lojas de um shopping e constataram que de 489 manequins apenas 46 deles são negros, o que corresponde a 9,4\%. Essas e outras imagens que insistem em dar mais visibilidade às peles claras do que às escuras fortalecem a compreensão das crianças e adultos/as de que o uso do "lápis cor de pele" é inquestionável e natural.

Entendemos que, para repensar a visualidade e suas implicações para o corpo e a subjetividade dos indivíduos, é importante a reflexão docente sobre os modos como olhamos e somos olhados pelos artefatos culturais, dentre eles, os manequins. Essa reflexão é necessária na formação de professores/as para incorporar na prática pedagógica a problematização da visualidade do cotidiano. Assim, os/as estudantes terão condições de questionar as imagens a sua volta e de olhar para além daquilo que é percebido de imediato. (SOUZA, BALISCEI E TERUYA, 2015, p.373).

Em nosso contato com as crianças, perguntamos o porquê pintavam as pessoas sempre com o mesmo padrão de cor: amarelo para os cabelos e rosa claro para a pele. Alguns/algumas responderam que pintavam assim porque "achavam ser mais bonito"; outros/as justificaram que "o denominado lápis 'cor de pele' foi feito para colorir a pele das pessoas independente da sua 'verdadeira' coloração". Essas respostas foram recebidas por nós como um diagnóstico, sinalizando a necessidade de discutir sobre as diferentes cores que podemos atribuir à pele. Necessidade esta que foi destacada em nossa intervenção, denominada de Cores da Nossa Pele - um espaço-tempo em que analisamos e debatemos a obra Polvo (2013 - 2014) da artista carioca Adriana Varejão (1964--).

Desta forma, elaboramos este artigo com o objetivo de problematizar o papel do/a professor/a de arte enquanto mediador/a na formação multicultural do sujeito contemporâneo. Para desempenhar tal objetivo, desenvolvemos uma pesquisa bibliográfica, que investiga essa temática a partir de artigos, livros, capítulos, dissertações e teses já produzidas (GIL, 2002). Além disso, também possui delineamento documental, uma vez que, conforme (EVANGELISTA, 2012) fotografias, filmes, músicas, desenhos e produções artísticas podem atuar como documentos investigativos a partir dos quais uma pesquisa é elaborada. Nesse caso, tomamos como documentos alguns desenhos de alunos e alunas do $3^{\text {a }}$ ano do Ensino Fundamental de uma escola pública da cidade de Maringá, Paraná, e as produções artísticas de Adriana Varejão. 
No estudo de imagens, debruçamo-nos também sobre o Estudo da Cultura Visual, uma trama teórico-metodológica em evidência, principalmente, a partir da década de 1980 e que repercute características do pós-estruturalismo e dos Estudos Culturais. Quando tomamos as imagens como documentos, (res)significando-as, mais do que nos ocupar com a leitura de imagens, interessamo-nos investigar os efeitos que as visualidades provocam em quem as vê. Assim como os professores/as e pesquisadores/as que se identificam com o estudo da Cultura Visual (TOURINHO, 2012; CUNHA, 2014; BALISCEI, 2014), consideramos que as imagens estão impregnadas de valores culturais que produzem e refletem concepções sociais, individuais e educativas. Concordamos que, assim como as demais produções expressivas, as imagens "[...] são portadoras e mediadoras de significados e posições discursivas que contribuem para pensar o mundo e para pensarmos a nós mesmos como sujeitos" (HERNÁNDEZ, 2011, p. 33). Nesse sentido, falar sobre e a partir do Estudo da Cultura Visual implica examinar questões mais abrangentes do que "o que o/a artista quis dizer com essa imagem", e levantar outras perguntas, como: "o que essa imagem diz sobre mim?"; "como ela me posiciona?" e "quem se beneficia com ela?".

Quanto à estrutura, organizamos nossa reflexão do seguinte modo: em um primeiro momento, apresentamos o trabalho de Adriana Varejão, cuja temática balizou nossas discussões e intervenções no Estágio Supervisionado em Artes Visuais e na pesquisa sobre multiculturalismo e diferença no contexto escolar. Posterior a isso, descrevemos os exercícios que desenvolvemos junto aos/às estudantes do $3^{\circ}$ ano do Ensino Fundamental, durante nossas intervenções na disciplina de Arte. Além disso, analisamos algumas imagens das produções das crianças que refletem os diálogos estabelecidos por nós. Por fím, antes de nossas considerações finais, inferimos sobre a importância e a necessidade de se problematizar as diferenças étnicas e raciais no espaço educacional e problematizamos o uso de estereótipos nos desenhos e pinturas escolares.

\section{A ARTISTA E SUA OBRA: O POVO BRASILEIRO EM UMA PALETA DE CORES}

A artista carioca Adriana Varejão nasceu em 1964 e até hoje vive e trabalha no Rio de Janeiro. Adriana Varejão iniciou sua carreira nos anos 80 e desde então tem recebido destaque nacional e internacional como artista plástica contemporânea. Suas obras ganharam destaque 
BALISCEI, J. P.; CALSA, G. C.; GODINHO, A. C. M.

pelas composições que retratam histórias e impactam o olhar do/a espectador/a ao apresentarlhes efeitos de peles rasgadas, sangramentos e sobreposição de vísceras obtidas com materiais diferenciados para fazer referência à carne e ao corpo humano e às suas aproximações com a arte (MORAES, 2013).

Língua com padrão sinuoso (1998) e Azulejaria verde em carne viva (2000), por exemplo, são algumas das produções da artista que foram organizadas de modo pouco convencional e que mesclam técnicas artísticas distintas que, juntas, provocam-nos estranhamentos por não delimitar precisamente as fronteiras entre realidade e ilusão. Como pode ser analisado abaixo (Fig. 1) é recorrente nos trabalhos da artista a presença de efeitos de ferimentos, cortes e deterioração da tela, semelhante ao que acontece com o corpo humano.

Fig. 1 - Efeitos, cortes e deterioração

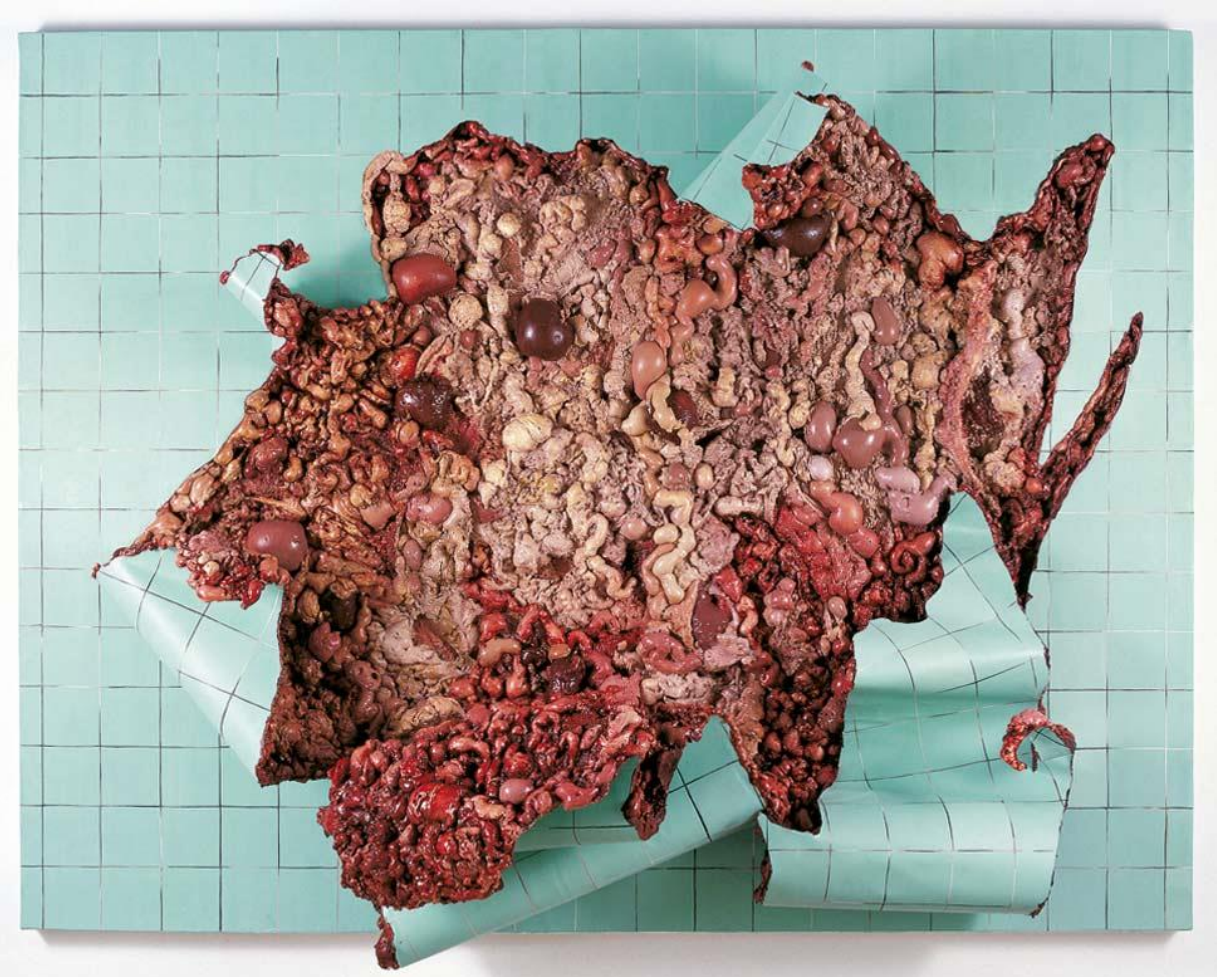

Azulejaria verde em carne viva, Adriana Varejão, 2000. Óleo sobre tela e poliuretano em suporte de alumínio e madeira.

Fonte: Moraes (2013, p. 23).

No que tange às referências mais explícitas e tradicionais à pele e ao corpo humano, podemos citar Mãe d'Água (2009) - uma produção elaborada em suporte arredondado onde a artista mescla técnicas artísticas distintas (Fig. 2).

Fig. 2 - Evidências de diferentes tons de pele 
CONFLITOS COM O "LÁPIS COR DE PELE":

A SÉRIE POLVO, DE ADRIANA VAREJÃO E O MULTICULTURALISMO NO ENSINO DE ARTE

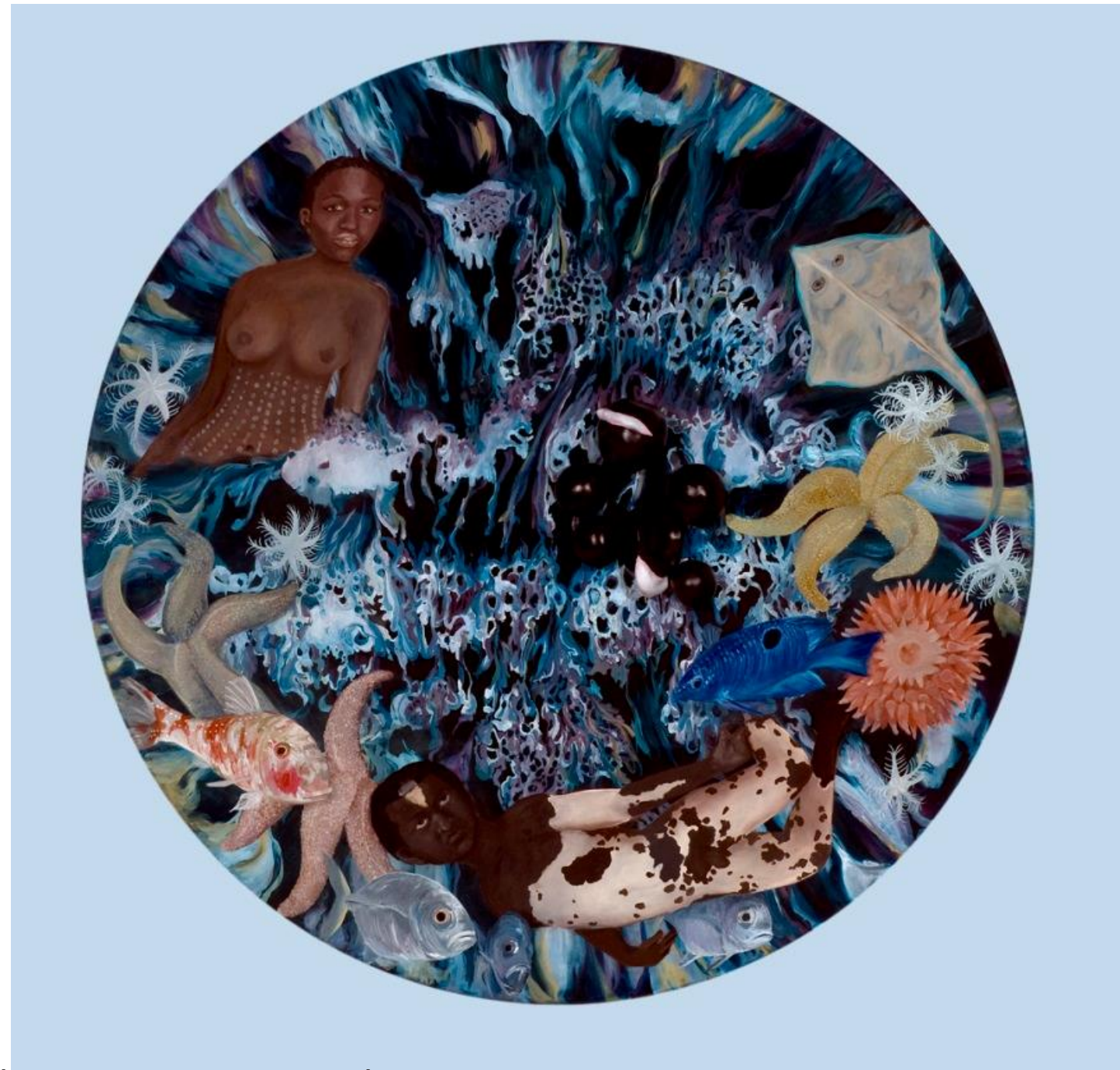

Mãe d'Água, Adriana Varejão, 2009. Óleo sobre fibra de vidro e resina.

Fonte: Moraes (2013, p. 25).

Nesta obra, verificamos características que são muito notáveis nas produções de Adriana Varejão, como as composições feitas pela junção de técnicas diferenciadas, o discurso crítico ou místico e a presença de narrativas fazendo referências às histórias reais ou fictícias. Além desses aspectos que caracterizam arte contemporânea e são recorrentes na poética da artista carioca, o que é mais relevante para a nossa reflexão são as maneiras como Adriana pinta e tonaliza as peles das personagens. Como se pode analisar, a personagem masculina, localizada na parte inferior da produção, tem sua pele preenchida por uma mescla entre o tom rosado e o marrom. 
BALISCEI, J. P.; CALSA, G. C.; GODINHO, A. C. M.

De início, interpretamos que nessa representação, possivelmente, a artista estaria fazendo menção visual ao vitiligo ${ }^{6}$ - doença caracterizada pela perda da coloração da pele e pelas lesões cutâneas - manchas brancas com tamanhos variáveis. Essa semelhança pode ser analisada em observação às Fig. 3 e 4, em que trazemos o detalhe da personagem destacada comparada à fotografia de uma pessoa com vitiligo.

Fig. 3 e 4 : Personagem de Adriana Varejão e o vitiligo
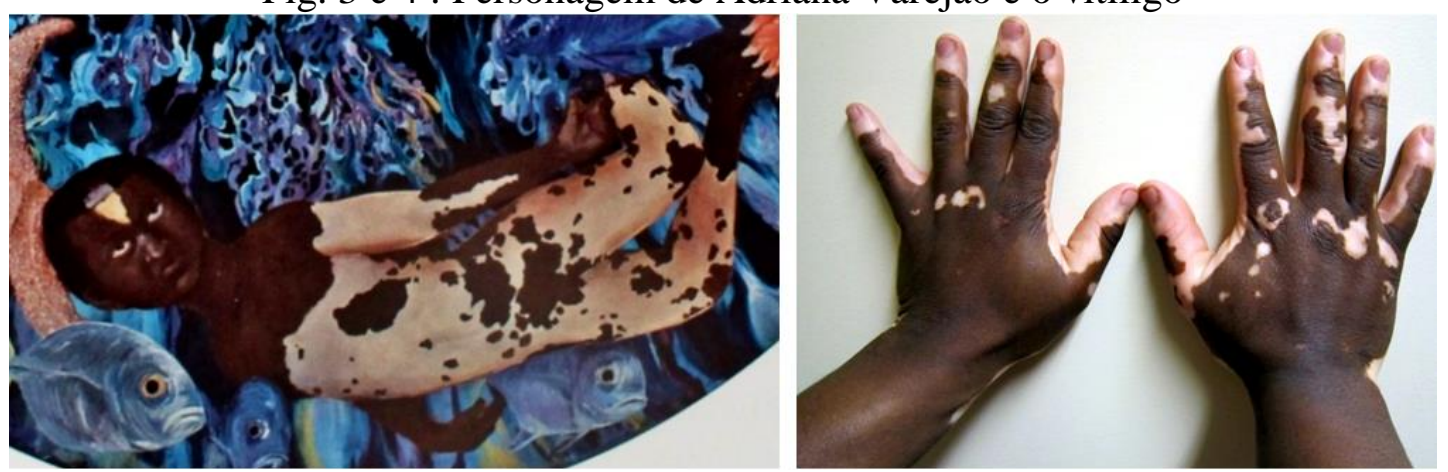

Detalhe da personagem da obra Mãe d'Água, Adriana Varejão (2009), e foto das mãos de uma pessoa com vitiligo.

Fonte: <http://remediodaterra.com.br/tratamentos-naturais-para-vitiligo/>. Acesso em: 02 de outubro de 2015.

Especificamente sobre essa obra e sobre a figura cujas cores são "mescladas", Schawarcz e Varejão (2014) argumentam que,

\begin{abstract}
Há ainda uma estranha figura que toma parte significativa do trabalho: trata-se de um moleque albino, ou desbotado, ou misturado. Se o menino é negro, seu corpo é malhado - meio branco, meio preto. Poderíamos dizer que ele está apenas doente: tem vitiligo. Mas num país como o nosso, em que a brancura é ainda considerada símbolo de superioridade e de elevação social, "ficar branco" poderia não ser uma moléstia, mas uma forma bem brasileira de "salvação". (SCHWARCZ E VAREJÃO, 2014, p.277, grifos nossos)
\end{abstract}

A partir de pesquisas realizadas sobre a obra, verificamos que nossas interpretações iniciais convergem com as análises tecidas pelas autoras, haja vista que a figura retratada na parte inferior da obra possivelmente remete-se a uma pessoa com vitiligo. Os grifos destacados por nós, em que as autoras denunciam que no Brasil a brancura ainda é símbolo de superioridade, parecem reforçar as inquietações e incômodos que sentimos quando, nas vivências com o Estágio Curricular, as crianças do $3^{\circ}$ ano do Ensino Fundamental elegeram o

\footnotetext{
${ }^{6}$ Segundo a Sociedade Brasileira de Dermatologia (SBD), tais lesões aparecem devido à diminuição ou ausência de melanócitos. Vale ressaltar que o vitiligo não é uma doença contagiosa. <http://www.sbd.org.br/doencas/vitiligo/>. Acesso em 02 de outubro de 2015.
} 
CONFLITOS COM O "LÁPIS COR DE PELE":

A SÉRIE POLVO, DE ADRIANA VAREJÃO E O MULTICULTURALISMO NO ENSINO DE ARTE

lápis rosa claro como o "correto" para o preenchimento da pele alegando que sua cor agregaria "beleza" aos seus desenhos.

A obra intitulada Polvo (2013-2014), que tem destaque em nosso artigo por ter sido apresentada e problematizada junto às crianças do $3^{\circ}$ ano, compõe um catálogo com 33 cores de tintas nos tons de pele dos brasileiros e brasileiras e uma série de autorretratos elaborados por Adriana Varejão. Esse conjunto artístico que configura a obra Polvo foi produzido pela artista a partir de uma pesquisa realizada pelo Instituto Brasileiro de Geografia e Estatística (IBGE). Na pesquisa em questão, os entrevistados e entrevistadas responderam à pergunta: “Qual a cor de sua pele?”. Amorenada, branca-sardenta, canelada, miscigenação, rosaqueimada, tostada, morena-ruiva, esbranquecimento, laranja e corada são alguns dos nomes que as pessoas escolheram para intitular a cor de sua pele. Dentre a variedade e criatividade dos termos, Adriana Varejão selecionou 33 deles para criar o catálogo de tintas Polvo, composto por 33 bisnagas de tinta óleo (Fig. 5).

Fig. 5: 33 tintas Polvo.

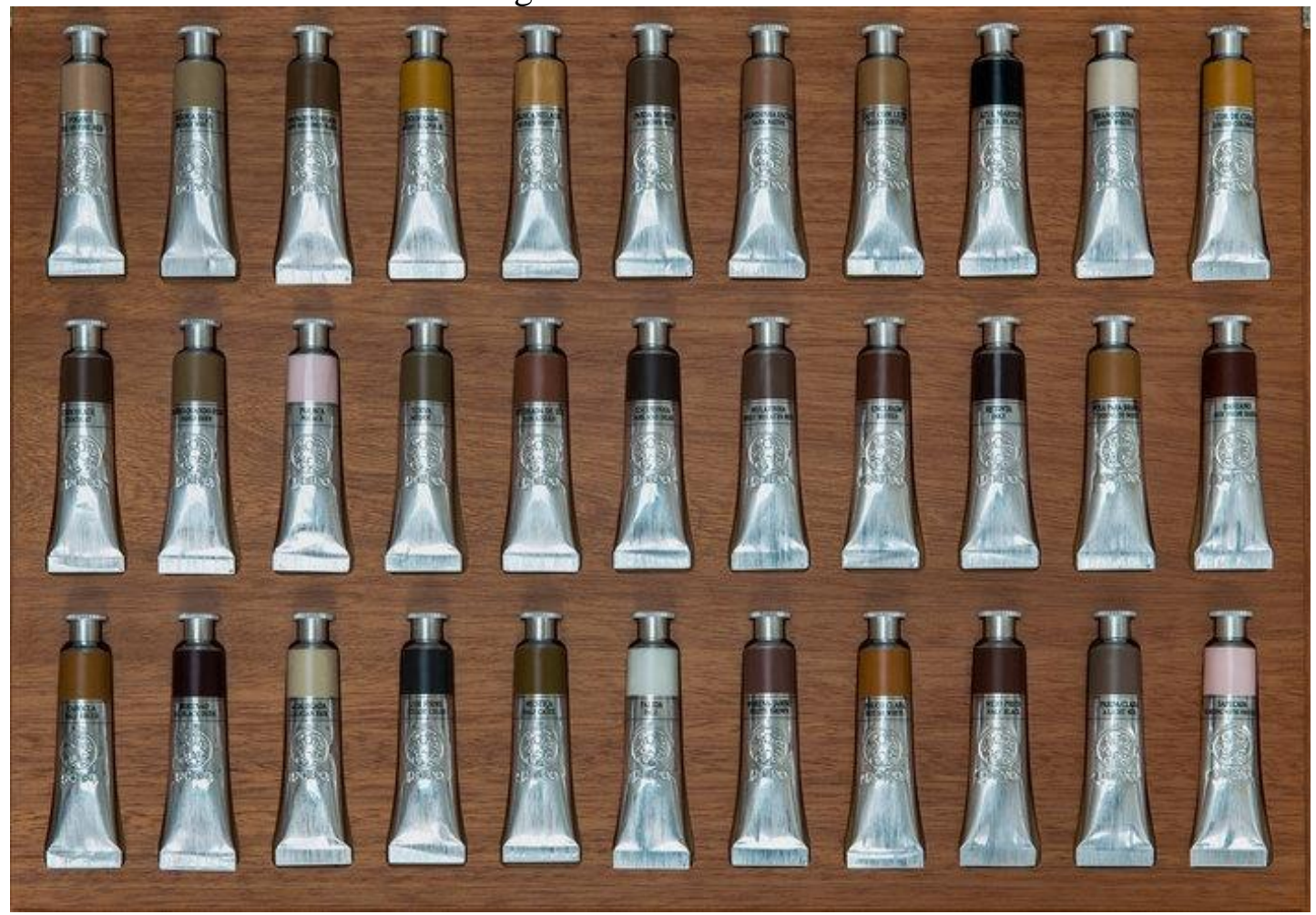

Estojo Tintas Polvo, Adriana Varejão, 2013-2014. Caixa de madeira com tampa de acrílico, contendo 33 tubos de alumínio e tinta a óleo.

Fonte: <http://www.victoria-miro.com/exhibitions/445/>. Acesso em -5 de set. de 2016.

Agalegada, Amarelosa, Azul-marinho, Bahiano, Branca-melada, Branca-suja, Branquinha, Bugresinha-escura, Burro-quando-foge, Cabocla, Cabo-verde, Café-com-leite, 
BALISCEI, J. P.; CALSA, G. C.; GODINHO, A. C. M.

Chocolate, Cor-de-cuia, Cor firme, Encerada, Escurinha, Fogoio, Meio-preta, Mestiça, Morena-bem-chegada, Morena-jambo, Mulatinha, Pálida, Parda-clara, Parda-morena, Polaca, Pouco-clara, Puxa-para-branca, Queimada-de-praia, Retinta, Sapecada e Turva ${ }^{7}$ são os termos que inspiraram e que intitulam os tubos de tinta de Adriana Varejão.

De imediato, podemos questionar: qual a relação entre o multiculturalismo brasileiro e o polvo? A escolha de tal animal para simbolizar a série de tintas não foi simplesmente ao acaso. As tintas que compõem a série Polvo (2013 -2014) receberam esse nome pelo fato de o animal possuir peculiaridades que envolvem sua pele e também para fazer referência às substâncias que libera para escapar de possíveis predadores.

[...] polvos, além de serem moluscos marítimos dos mais complexos - da ordem dos Octopoda, desses que têm oito pés ou braços, e ventosas -, liberam a substância da tinta chamada melanina, a mesma que da cor à pele e ao cabelo dos seres humanos. [...] outra particularidade desse espécime. Para se defender dos predadores os polvos são capazes de se camuflar, trocando a cor da pele, a partir de diferentes pigmentos: amarelo, laranja, vermelho, preto e até marrom. (SCHWARCZ E VAREJÃO, 2014, p. 339, grifos nossos).

Como destacado na citação, para fugir de possíveis predadores, o polvo consegue se camuflar utilizando pigmentação específica. Em nossa análise, nós também podemos "colorir nossas peles" combinando ou acrescentando a elas diferentes pigmentos e culturas, multiculturalizando-as. A troca multicultural a qual nos referimos pode ser visualmente percebida na série de Varejão quando, juntamente com o estojo de tintas, produz e expõe 11 autorretratos nos quais se "camufla" em meio a cores e peles diferentes. Para isso, Varejão utilizou as tintas produzidas por ela, anteriormente.

Como podemos notar na Fig.6, as três telas, que possuem o mesmo tamanho, têm como temática autorretratos onde Varejão se projeta com cores diferentes, como se, com isso, demonstrasse sua mestiçagem e o multiculturalismo que a integram. Além disso, no rodapé das pinturas, a artista traz uma escala de cores chamando atenção para outras combinações e nuances a partir das quais somos culturalmente produzidos, como as escalas de cores em tons de cinza, rosa e azul.

Fig. 6: Polvo Portraits I (Classic Series), 2013. Óleo sobre tela, 3 telas de 80 x $65 \mathrm{~cm}$.

\footnotetext{
${ }^{7}$ Aqui, descrevemos os termos respeitando a grafia original (SCHWARCZ E VAREJÃO, 2014). 
CONFLITOS COM O "LÁPIS COR DE PELE":

A SÉRIE POLVO, DE ADRIANA VAREJÃO E O MULTICULTURALISMO NO ENSINO DE ARTE
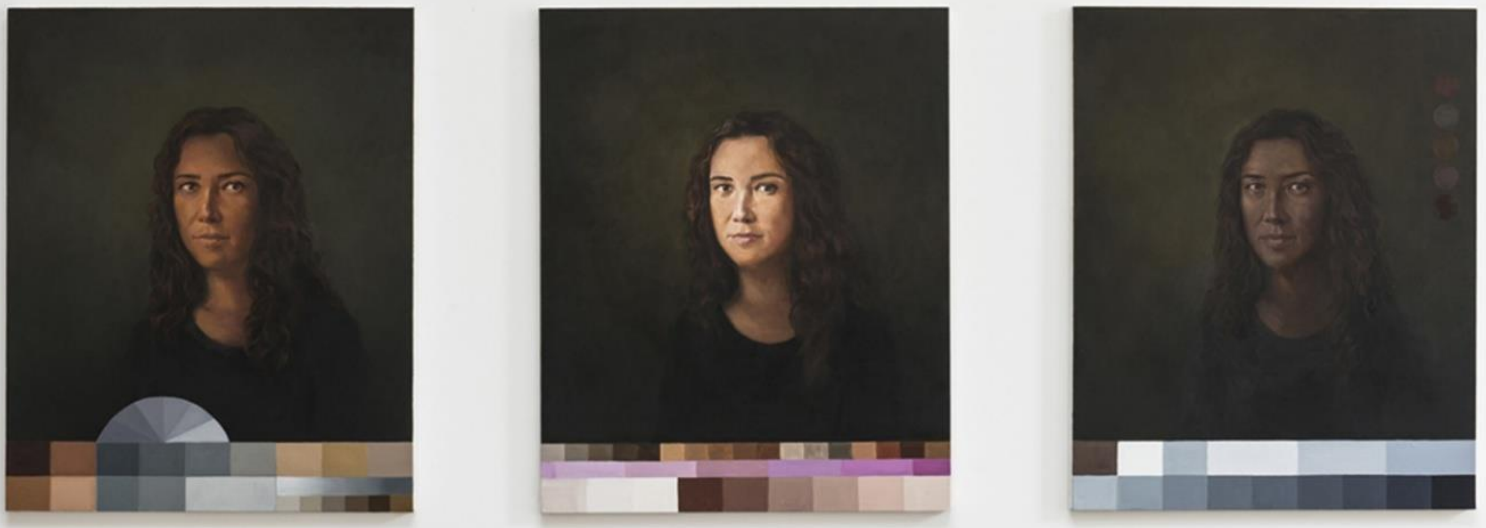

Polvo Portraits I (Classic Series), Adriana Varejão, 2013. Óleo sobre tela. Fonte: SCHWARCZ E VAREJÃO, 2014, p.346-348.

Em outras produções que também compõem a série Polvo, Adriana Varejão utilizou-se das tintas confeccionadas a partir da entrevista feita pelo IBGE para preencher pequenas partes de seu rosto, conforme apresentamos na Fig.7. A artista se autorretrata com tons acinzentados e sépia e destaca fragmentos específicos de seu rosto, colorindo-os com diferentes tonalidades, demonstrando que são múltiplas as cores de pele. Nessas obras, semelhante às pinturas tribais, Varejão se autorretrata com tiras e formas geométricas sobrepostas aos seus olhos, boca, nariz e testa.

Fig. 7: Multiculturalize(-se).
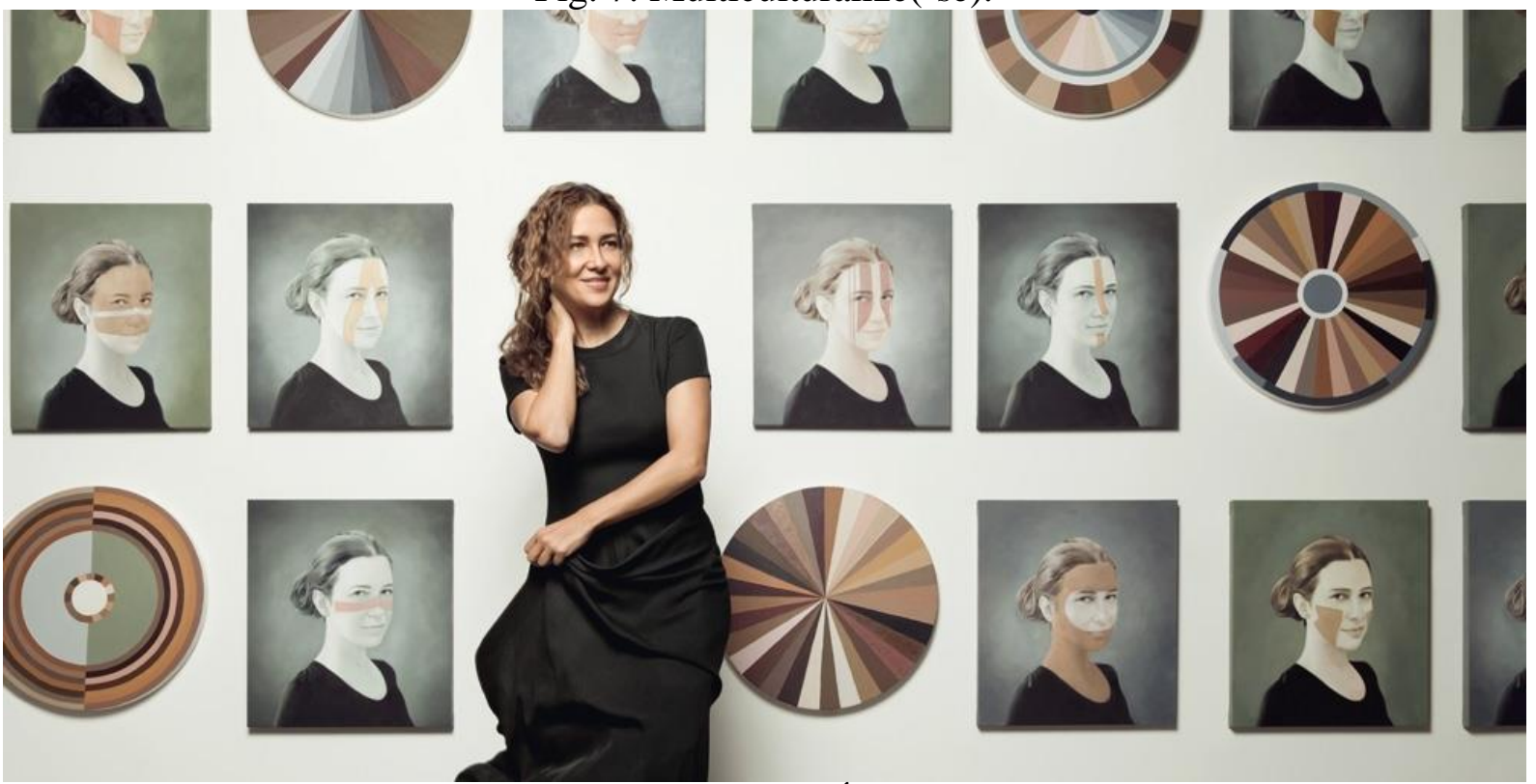

Polvo Portraits (China Series), Adriana Varejão, 2014. Óleo sobre

Fonte: <http://revistatrip.uol.com.br/tpm/adriana-varejao>. Acesso em 05 de set. de 2016. 
BALISCEI, J. P.; CALSA, G. C.; GODINHO, A. C. M.

Observando a obra da artista e o modo como ela se retratou com as mais diferentes tonalidades de pele, notamos que a série Polvo (2013-2014) não legitima e autoriza apenas uma única "cor de pele"- o rosa claro -, mas, ao contrário disso, enfatiza as diversas combinações e possibilidades que existem entre as cores e culturas em uma paleta de tons variados. Sobre isso, a artista comenta que pele é "[...] território; é casa e morada. Talvez por isso, esse último trabalho [a série Polvos] reflita muitos de seus projetos. Trata-se, assim, de uma reflexão sobre cor, pele, pintura e criar a partir do próprio ato de criação e classificação. (SCHWARCZ E VAREJÃO, 2014. p. 339).

Nesse sentido, insatisfeitos e provocados com os comentários que as crianças do $3^{\circ}$ ano do Ensino Fundamental faziam, enaltecendo e autenticando uma única cor para preencher e pintar a pele, por meio da série Polvo (2013-2014) e das temáticas propostas por Adriana Varejão, sentimo-nos motivados a problematizar o - até então naturalizado - "lápis cor de pele". A seguir, descrevemos nossa organização para apresentar a artista e a sua produção aos alunos e alunas do $3^{\circ}$ ano do Ensino Fundamental e para questionar sobre aquilo que denominavam de "cor de pele".

\section{A PROPOSTA "CORES DA NOSSA PELE"}

Com auxílio de imagens impressas e de projeção, analisamos e exploramos a produção de Adriana Varejão junto aos/às alunos/as, contando-lhes sobre sua história e sobre a criação da série Polvo (2013-2014). Na ocasião, propomos uma prática semelhante àquela experimentada por Varejão - o que causou alvoroços e expectativas nas crianças. Cada estudante foi orientado/a a misturar tintas para produzir um tom que se aproximasse o máximo possível da cor de sua pele. Para isso, os meninos e meninas foram acrescentando ao dorso de sua mão uma variedade de pigmentos, misturando-os. Tendo atingido uma cor que se aproximasse à cor do dorso da mão, as crianças do $3^{\circ}$ ano do Ensino Fundamental, individualmente, pensaram e elegeram um nome para intitular a "sua cor". Nomes como Algodão doce, Molho de Maçã, Café com Leite e Chocolate intitularam as cores criadas pelos alunos e alunas. Fazendo referência ao estojo de tintas de Varejão, distribuímos as tintas em recipientes, identificados com os nomes dos/as alunos/as e com os nomes que atribuíram à cor.

Com base nos resultados produzidos a partir da proposta que denominamos Cores de nossa pele (2014), aplicamos, em nosso último dia de intervenção, um exercício de autorretrato com o intuito de incentivar os alunos e alunas a utilizarem suas próprias tintas 
CONFLITOS COM O "LÁPIS COR DE PELE":

A SÉRIE POLVO, DE ADRIANA VAREJÃO E O MULTICULTURALISMO NO ENSINO DE ARTE

para a pintura e, com isso, desestabilizar a naturalização do "lápis cor de pele" como o "correto/único possível" para se autorretratar. Para isso, entregamos a eles/as pequenos espelhos e pedimos que os usassem para observar os detalhes de seus rostos, como o formato dos olhos, nariz, boca, o desenho das sobrancelhas, etc., orientando-os/as para que se atentassem aos seus próprios traços e linhas de expressão (Fig. 8, 9 e 10).

Fig. 9, 10 e 11: Produção dos/as estudantes do $3^{\circ}$ ano do Ensino Fundamental
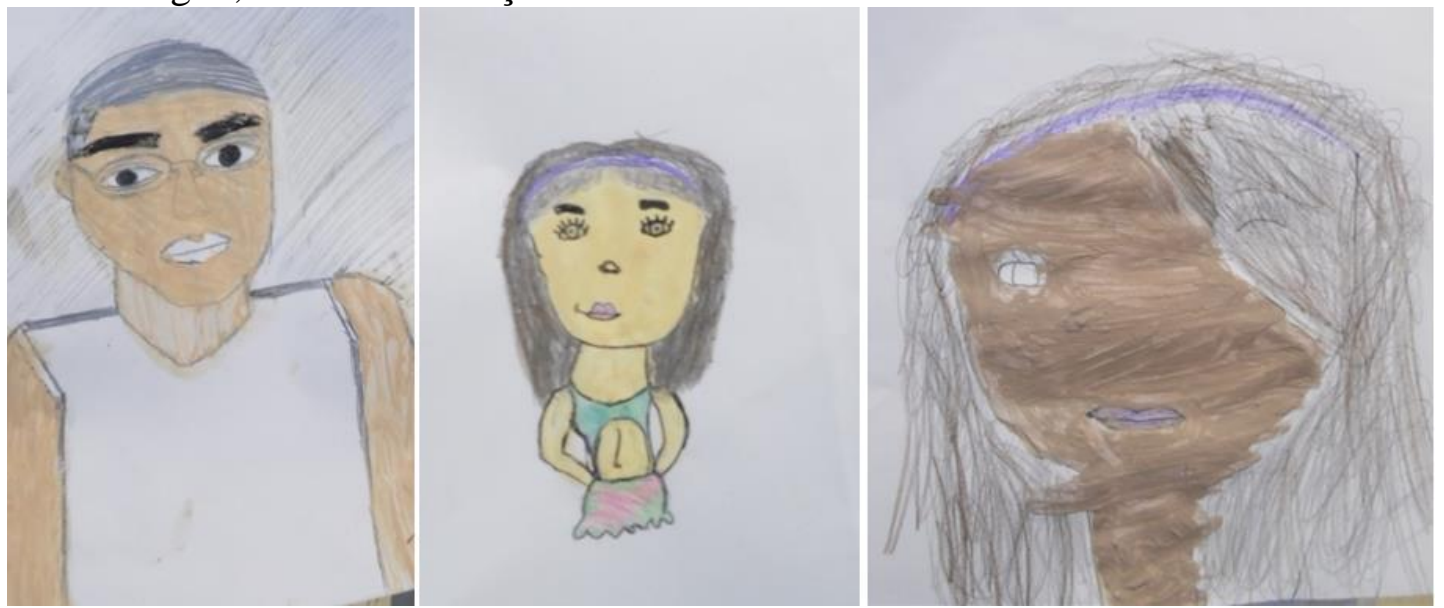

Fonte: registro e arquivo pessoal, 2014.

A criação de autorretratos contribuiu para que os/as estudantes pudessem notar as peculiaridades e as diferenças que integravam seus rostos e para que esses detalhes fossem reproduzidos no papel, posteriormente. Uns/umas preferiram somente desenhar o rosto, outros/as desenharam o corpo inteiro, e outros/as, ainda, acrescentaram cenários e objetos à composição. A partir da investigação dos autorretratos percebemos que as crianças materializaram em suas produções o multiculturalismo valorizado nas obras de Varejão, pois, apresentaram traços, cores, texturas e formas expressivas que, em nossa análise, distanciam-se daquelas que integravam seus desenhos iniciais, pintados com o lápis rosa claro.

\section{A IMPORTÂNCIA DE QUESTIONAR ESTEREÓTIPOS NO AMBIENTE ESCOLAR}

Ao sistematizarmos nossa experiência com o Estágio Supervisionado em Artes Visuais em um artigo temos a intenção de compartilhar e levantar questionamentos como: por que o "lápis cor de pele" tem tom rosa claro e não tom marrom? Os professores e professoras se preocupam em problematizar o uso e reprodução deste estereótipo nos desenhos? Por que 
BALISCEI, J. P.; CALSA, G. C.; GODINHO, A. C. M.

mesmo os alunos e alunas de pele mais escura escolhem lápis de tons claros como o padrão de pele em suas pinturas? Essa padronização é recorrente também nas imagens que os professores e professoras apresentam aos/às estudantes e naquelas que "decoram" o espaço escolar? Quais estratégias poderiam ser pensadas para ampliarmos o repertório infantil no que tange às cores da pele?

Esse conjunto de perguntas destaca a necessidade de investigarmos os discursos e representações que as imagens escolares e não escolares fazem circular. Se tomarmos as imagens como artefatos culturais e a cultura como um espaço de luta por representatividade, não é conveniente consentirmos com a hegemonia de figuras de personagens com as mesmas características - sujeitos brancos, loiros, cristãos e heterossexuais. Além disso, como demonstram Baliscei, Calsa e Stein (2015), quando sujeitos não-brancos são representados pelas imagens midiáticas, como o cinema e a televisão, ocupam espaços marginalizados e ações específicas, como jogar basquete, fazer piadas e servir personagens brancos. Em análise da animação A Princesa e o Sapo (2009), os autores e a autora examinam que Tiana, a primeira e única princesa negra da Disney, passa 69\% do tempo do filme transformada em rã o que tira o foco da negritude da personagem. Além disso, diferente das demais princesas que são demasiadamente associadas à doçura e à bondade, Tiana é ambiciosa e egoísta chegando a beijar o príncipe da história a troco de dinheiro.

Segundo Santomé (2012) as diferenças culturais são formadas a partir de uma relação de construção e desconstrução estabelecida por e nas relações sociais, inclusive, naquelas que permeiam o espaço e o currículo escolar. O autor chama atenção para as maneiras como algumas culturas, como as das minorias étnicas e as dos povos do terceiro mundo, são deturpadas e/ou invisibilizadas pelas ações e conhecimentos escolares.

No ambiente escolar, ainda que crianças e adultos/as de várias culturas compartilhem do mesmo espaço físico, as diferenças operam de maneiras assimétricas, hierarquizadas, aproximando-se daquilo que Candau (2011) denomina como Multiculturalismo Assimilacionista. Tal abordagem tem como característica a prescrição, uma vez que cria situações para que todos/as incorporem a cultura hegemônica, quando, por exemplo, incentiva que as crianças, independente de sua cor e etnia, concedam ao lápis rosa claro o status de "lápis cor de pele". Para Candau (2011, p. 246)

No caso da educação, [na abordagem multicultural assimilacionista] promove-se uma política de universalização da escolarização. Todos e todas são chamados a participar do sistema escolar, mas sem que se coloque em questão o caráter monocultural presente na sua dinâmica, tanto no que se refere aos conteúdos do 
currículo, quanto às relações entre os diferentes atores, às estratégias utilizadas nas salas de aula, aos valores privilegiados etc.

Ainda que todos/as sejam convidados a integrar o mesmo espaço físico, na abordagem multicultural assimilacionista as hierarquias culturais permanecem e se não houver mediação e intervenção pedagógica intencional, com o passar o tempo, essa frequência de desigualdade, discriminação e preconceito é naturalizada, como ocorre na valorização do lápis rosa claro e tudo o que ele representa. A cultura escolar fundada a partir dos moldes hegemônicos prioriza a homogeneidade e o uniforme, logo, as discussões sobre as diferenças culturais tendem a ser evitadas e ignoradas. Nas palavras da autora,

[...] a preocupação com as diferenças culturais é vista frequentemente como algo "externo", recentemente incorporado a este campo [o educacional], constituindo como um corpo estranho às suas preocupações e, de alguma forma, responsável por deslocar seu olhar para aspectos considerados não articulados ou fragilmente relacionados às questões nucleares que estruturam as práticas pedagógicas no cotidiano escolar. (CANDAU, 2011, p. 241).

Ao problematizarmos o uso do "lápis cor de pele", buscamos nos aproximar do Multiculturalismo Interativo, também chamado de Interculturalidade (CANDAU, 2011). Nessa abordagem multicultural não há hierarquias entre as diferenças manifestadas nos gestos, gêneros, etnias e sexualidades, e as intervenções pedagógicas, por sua vez, agem em prol da diminuição das assimetrias culturais favorecendo ambientes e situações de troca de conhecimentos. Quando buscamos destacar que, além do rosa claro, as outras cores como o marrom, vermelho, preto, amarelo, entre outras, também podem preencher e representar as peles, movimentamo-nos ao encontro do multiculturalismo interativo e convidamos as crianças a perceberem suas diferenças e as diferenças dos/as outros/as, valorizando-as.

Segundo Bastos (2015) pode-se dizer que as relações de respeito, reconhecimento e harmonia, entre negros/as e brancos/as no espaço educacional têm aumentado. No entanto, ainda existe uma grande barreira a ser ultrapassada até que se possa dizer que tais relações se estruturam de igual para igual, de modo harmônico. Professores e professoras precisam desenvolver estratégias que englobem assuntos antirracistas em suas propostas pedagógicas, pois, como destaca a autora, é também e principalmente no território escolar que a construção das identidades se estabelece. Para além da família, é na escola que alunos e alunas tomam conhecimento de culturas raciais e sociais distintas e legitimam comportamentos (de respeito, negação, repúdio, aproximação, etc.) para com aqueles/as que lhes são diferentes. 
BALISCEI, J. P.; CALSA, G. C.; GODINHO, A. C. M.

Muitas vezes professoras e professores carregam a tensão de acreditar nessa luta, mas, por não sentirem na própria experiência os efeitos de uma sociedade hierarquizada a partir da raça, por exemplo, acabam negligenciando esse conhecimento na sua prática profissional cotidiana. [...]. Professores e professoras têm um papel estratégico no desenvolvimento de pesquisas e na formulação de práticas pedagógicas que reflitam o ideal de uma educação antirracista e antissexista [...] (BASTOS, 2011, p. 617-618).

Com isso, ao nos depararmos com discussões sobre preconceitos e diferenças, somos remetidos/as a tudo aquilo que se encontra à margem do que é denominado como "padrão" dentro de nossa sociedade, seja no âmbito racial, cultural, religioso, estético, sexual ou de gênero. Essa padronização tem sido encontrada fora e dentro do espaço escolar onde, infelizmente, mesmo frente aos avanços pedagógicos, ainda deparamo-nos com profissionais que não valorizam as diferenças e alunos/as que reproduzem bagagens culturais firmadas no bojo da família e da sociedade, muitas vezes preconceituosas.

Como consequência dessas cargas de preconceitos não questionadas, em nossas vivências junto ao Estágio Curricular observamos estudantes que parecem anular suas arestas culturais, representando-se de maneira padronizada em seus desenhos - ainda que tais representações pouco ou nada se assemelhem à realidade. Esses desenhos foram coloridos com apenas uma única possibilidade de cor de pele, o que indica a supremacia da pele clara. $\mathrm{Na}$ ocasião, além da valorização do lápis rosa claro como a única "cor de pele", sentimo-nos incomodados/as pela (falta de) ação da professora que não buscou meios para modificar, ou ao menos problematizar, a postura de seus alunos e alunas durante as aulas.

Moreira (2008) descreve que já na Educação Infantil a escola tem um importante papel de preparar a criança para viver em sociedade. Argumenta que, além de proporcionar o desenvolvimento da coordenação motora, da linguagem e o aprendizado dos cuidados com o corpo e com a higiene pessoal, os professores, professoras e demais profissionais que atuam neste espaço, exercem funções pedagógicas, políticas e sociais que ultrapassam o assistencialismo. Ao preparar as crianças para a vida em sociedade a escola acaba privando-as de expressar algumas de suas vontades e sentimentos, o que irá futuramente influenciar, inclusive, na prática de desenho. A autora destaca que a escola forma e transforma as maneiras como as crianças desenham, pois, muitas vezes preocupados/as em cumprir aos apelos dos/as familiares e dos/as gestores/as, os professores e professoras tendem a dar mais importância à alfabetização do que à expressividade de seus alunos e alunas. No caso do ensino de Arte, a área central de nosso conhecimento e pesquisa, as intervenções se tornam mais simplistas e reducionistas: atividades para colorir, desenhos mimeografados, painéis elaborados a partir de moldes e outros trabalhos manuais semiprontos, apenas para serem 
montados de acordo com as instruções. Na análise de Moreira (2008), intervenções como essas resumem a relação professor/a-aluno/a à hierarquias onde as crianças fazem somente aquilo que os/as adultos/as mandam.

\begin{abstract}
A uniformidade que encontramos em desenhos de crianças de uma mesma classe é a tradução desta relação autoritária. Todos temos na lembrança, as casinhas, os coelho $e$ outros modelos, que são repetidos incansavelmente por todas as crianças numa sala de aula; sejam estes desenhos copiados da lousa, ou mimeografados pelas professoras para as crianças colorirem. E ninguém percebe que estas são atividades puramente mecânicas, que nada contribuem para o desenvolvimento das crianças. (MOREIRA, 2008, p. 84, grifos nossos).
\end{abstract}

Além das casinhas e dos coelhos citados pela autora, podemos mencionar outros desenhos estereotipados recorrentes nos desenhos feitos por crianças e adultos/as, como por exemplo, a cor rosa clara atribuída ao preenchimento das áreas referentes à pele e a cor amarela às áreas referentes aos cabelos. Em comum, esses desenhos apresentam formas e cores estereotipadas, isto é, um modelo, um padrão de representação que é fielmente seguido e que não pode ser "profanado".

Por serem basicamente os mesmo, os estereótipos de tão reproduzidos, multiplicados e utilizados, se tornaram largamente difundidos e aceitos, constituindo-se já em uma espécie de estereótipos mentais, isto é, os clichês estão armazenados nas gavetas de nosso cérebro e basta querermos para que nossas mãos consigam, sem muito esforço, representá-los. (VIANNA, 2012, p.57).

Concordamos com Vianna (2012) para quem os desenhos e formas estereotipados são elaborados quase que automaticamente. Portanto, quando selecionam cores para pintar os desenhos, as crianças também exercitam e reproduzem ações estereotipadas que são prejudiciais tanto para a educação em sociedade quanto para o ensino das técnicas de Arte. Em outro estudo relativo ao Estágio Supervisionado em Artes Visuais, Baliscei, Stein e Lacerda (2015) também evidenciaram a presença de desenhos estereotipados em espaços educativos. $\mathrm{O}$ "[...] preenchimento uniforme e chapado, onde as cores não se misturam ou se sobrepõem, a ausência de textura, representações antropomórficas (como no sol) e a utilização de esquemas e estruturas repetidos (como nas flores e na grama)" são exemplos apontados pelos autores e autora para sinalizar que as formas estereotipadas buscam achatar as diferenças, reduzindo-as a representações simplificadas que desconsideram nuances e peculiaridades (BALISCEI; STEIN E LACERDA, 2015, p.115). 
BALISCEI, J. P.; CALSA, G. C.; GODINHO, A. C. M.

Quando elegem o "lápis cor de pele", a estereotipia é recorrente não pelo uso de traços, texturas e formas repetitivas, como nos exemplos apontados acima, mas sim pelo uso exclusivo de determinada cor, no caso, o rosa claro. Todas as árvores "devem" ser verdes; todo céu "deve" ser azul; toda flor "deve" ter pétalas vermelhas; todo menino "deve" usar roupas azuis e toda menina "deve" usar roupas rosas; todo cabelo "deve" ser loiro e, por fim, toda pele "deve" ter tons claros e rosados; toda pele "deve" ser pintada com o "lápis cor de pele".

\section{CONSIDERAÇÕES FINAIS}

As experiências com os exercícios desenvolvidos em uma escola pública de Maringá, Paraná, durante a disciplina de Estágio Supervisionado em Artes Visuais, provocaram incômodos e inquietações sobre o ensino de Arte. Incômodos estes que nos levaram a questionar quais estratégias pedagógicas podem ser pensadas para o questionamento do uso do lápis de cor denominado "cor de pele" como o único possível para o preenchimento e caracterização da pele. Por isso, ao observarmos os alunos e alunas que, involuntariamente, reproduziam desenhos estereotipados e utilizavam cores padronizadas, motivamo-nos a discutir a dominação estético-cultural do "lápis cor de pele" nos desenhos produzidos pelas crianças dentro e fora dos espaços escolares.

Quando observamos os desenhos dos alunos e alunas em sala percebemos o quanto são condizentes a um padrão estético e cultural ao qual, inclusive, muitas vezes, não os representa. Seus desenhos são bastante parecidos entre si. Pintados, na maior parte das vezes, com as mesmas cores e delimitados por traços contínuos e rígidos, característicos dos estereótipos. Existe uma uniformidade que padroniza os desenhos das crianças e adultos/as, dificultando o desenvolvimento de traços com texturas e ritmos visuais diferentes. Compreendemos que os estereótipos materializados nos desenhos infantis podem influenciar comportamentos preconceituosos como, por exemplo, a construção de opiniões e julgamentos sobre o que é "bonito" e "feio", "certo" e "errado" e "melhor" e "pior".

Por fim, nossas considerações são as de que cabe também a nós, professores e professoras, pesquisadores e pesquisadoras do ensino de Arte, proporcionar aos alunos e alunas mudança(s) nas maneiras de olhar aquilo que é legitimado como o padrão e que é fielmente seguido dentro das salas de aula desde as séries iniciais. Sendo assim, destacar, questionar e discutir a respeito dos estereótipos e sobre as cores que utilizamos para preencher 
CONFLITOS COM O "LÁPIS COR DE PELE":

A SÉRIE POLVO, DE ADRIANA VAREJÃO E O MULTICULTURALISMO NO ENSINO DE ARTE

as imagens que elaboramos são premissas que podem auxiliar a desnaturalizar e desestabilizar comportamentos que os/as estudantes manifestam em seus desenhos, pensamentos e ações.

\title{
CONFLICTS WITH "SKIN COLOR PENCIL": THE POLVO (OCTOPUS) SERIES, ADRIANA VAREJÃO AND MULTICULTURALISM IN THE ART TEACHING
}

\begin{abstract}
Based on past experiences with the students of the 3rd grade of elementary school to a public school in Maringá, Paraná, this article has aimed to question the role of art teacher as intermediate in multicultural education of the contemporary subject. From the discussions about the color stereotypes, we think of possible teaching strategies to question the use of "skin color pencil " and develop reflections on the naturalness with which is choosen to paint, such as the use of other color was "forbidden". Was that the only possible pencil for filling and characterization of the skin? To discuss these aspects, we approach the Polvo (Octopus) series, the artist Adriana Varejão, multiculturalism and Art teaching practices. We believe that question about stereotypes in the classroom provides students with reflections that can change their looks and behavior in the face of differences.
\end{abstract}

Key - words: Education; Stereotype; Childhood; Visualities; Culture

\section{CONFLICTOS CON EL "LÁPIZ DE COLOR DE LA PIEL": LA SERIE POLVO (PULPO), ADRIANA VAREJÃO Y EL MULTICULTURALISMO EN EL ENSEÑANZA DEL ARTE}

\section{Resumen}

Basado en experiencias pasadas con los alumnos y alumnas del 3er grado de primaria a una escuela pública en Maringá, Paraná, este artículo tiene como objetivo discutir el papel del 
BALISCEI, J. P.; CALSA, G. C.; GODINHO, A. C. M.

maestro o maestra de arte como mediador/a en la educación multicultural del sujeto contemporáneo. A partir de las discusiones acerca de los estereotipos de color, pensamos en posibles estrategias de enseñanza para cuestionar el uso del "lápiz de color de la piel" y desarrollar reflexiones sobre la naturalización con la que es elegido para pintar dibujos, tales como si el uso de otro color fue "prohibido". Esta es la única lápiz posible para la caracterización de la piel? Para discutir estos aspectos, nos acercamos a la serie Polvo (Pulpo), de la artista Adriana Varejão, las prácticas del multiculturalismo y la enseñanza del arte. Creemos que la pregunta sobre los estereotipos en el aula ofrece a los y las estudiantes con reflexiones que pueden cambiar su apariencia y comportamiento frente a las diferencias.

Palabras - clave: Educación; Estereotipo; Infancia; Visualidades; Cultura

\section{REFERÊNCIAS}

BALISCEI, João Paulo. Os artefatos visuais e suas pedagogias: reflexões sobre o ensino de arte. 2014. 140 f. Dissertação (Mestrado em Educação) - Universidade Estadual de Maringá, Maringá.

BALISCEI, J. P.; CALSA, G. C.; STEIN, V. Estereótipos Raciais nos Filmes Disney: A Princesa Negra que encontrou a felicidade na servidão. Revista Invisibilidades, Porto, n. 8, p.57-68, jul./dez. 2015. Disponível em:

<https://issuu.com/invisibilidades/docs/revista_invisibilidades_n8_web> . Acesso em 06 de jun. 2016.

BALISCEI, J. P.; STEIN, V.; LACERDA, E. A. A organização dos espaços educativos: Reflexões e intervenções sobre imagens estereotipadas. Revista Educação Gráfica, Bauru, vol. 19, n. 2, p. 109-121, jul./dez. 2015. Disponível em:

$<$ http://www.educacaografica.inf.br/artigos/a-organizacao-dos-espacos-educativos-reflexoese-intervencoes-sobre-imagens-estereotipadas-organization-of-educational-spaces-reflectionsand-interventions-on-stereotyped-images>. Acesso em 10 de jan. 2016.

BASTOS, Priscila da Cunha. Eu nasci branquinha: construção da identidade negra no espaço escolar. Revista Eletrônica de Educação, v. 9, n. 2, p. 615-636, 2015.

CANDAU, Vera M. F. Diferenças culturais, Cotidiano Escolar e Práticas Pedagógicas. Currículo sem fronteiras, v. 11, p. 240-255, 2011.

CUNHA, Susana Rangel Vieira da. Imagens na Educação Infantil como Pedagogias Culturais. In: MARTINS, R.; TOURINHO, I. (Orgs.). Pedagogias culturais. Santa Maria: Ed. da UFSM, 2014.

EVANGELISTA, Olinda. Apontamentos para o trabalho com documentos de política educacional. In: ARAUJO R. M. L.; RODRIGUES, D. S. (Org.). A pesquisa em trabalho, educação e políticas educacionais. - Campinas, SP: Alínea, 2012. 
CONFLITOS COM O "LÁPIS COR DE PELE":

A SÉRIE POLVO, DE ADRIANA VAREJÃO E O MULTICULTURALISMO NO ENSINO DE ARTE

GIL, Antônio Carlos. Como elaborar projetos de pesquisa. - São Paulo: Atlas, 2002.

HERNÁNDEZ, Fernando. A cultura visual como um convite à deslocalização do olhar e ao reposicionamento do sujeito. In: MARTINS, R.; TOURINHO, I. (Orgs.). Educação da Cultura Visual: Conceitos e contextos. Santa Maria: Ed. da UFSM, 2011.

MORAES, Marcos. Adriana Varejão. Coleção Folha Grandes Pintores Brasileiros. São Paulo, 2013.

MOREIRA, Ana Angélica Albano. $O$ espaço do desenho: a educação do educador. São Paulo: Edições Loyola, 2008.

OLIVEIRA, Marilda Oliveira de. O estágio curricular como campo de conhecimento e suas especificidades. In: OLIVEIRA, M. O.; HERNÁNDEZ, F. A formação do professor e o ensino das Artes Visuais. - Santa Maria, ed. UFSM, 2005, p. 57-72.

VIANNA, Maria Letícia Raun. Desenhos estereotipados: um mal necessário ou é necessário acabar com este mal?. Advir, Rio de Janeiro, n.5, p. 55-60, 1995. Disponível em:

$<$ http://artenaescola.org.br/sala-de-leitura/artigos/artigo.php?id=69343\&>. Acesso em: $28 \mathrm{de}$ dez. 2016.

SANTOMÉ, Jurjo Torres.As culturas negadas e silenciadas no currículo. In: SILVA, Tomaz Tadeu da (Org.). Alienígenas na sala de aula. Petrópolis, RJ: Vozes, 2012.

SCHWARCZ, L. M.; VAREJÃO, A. Pérola imperfeita: A história e as histórias na obra de Adriana Varejão. Rio de Janeiro: Cobogó, 2014.

SOUZA, M. C.; BALISCEI, J. P.; TERUYA, T. K. Representações visuais na modernidade líquida: o que os manequins falam de nós? Revista Educação da UFSM, Santa Maria:

Universidade Federal de Santa Maria, vol. 40, n 2, mai./ago. 2015.

http://dx.doi.org/10.5902/1984644414198

TOURINHO, I.; MARTINS, R. Circunstâncias e ingerências da Cultura Visual. In: MARTINS, R.; TOURINHO, I. (Orgs.). Educação da Cultura Visual: conceitos e contextos. Santa Maria: Ed. UFSM, 2011.

UEM. Resolução n. ${ }^{\circ}$ 061/2010-CI/CCH: Aprova o projeto pedagógico do Curso de Graduação em Artes Visuais. 2010. Disponível em:

<http://www.cch.uem.br/resolucoes_10/061_10.pdf>. Acesso em 10 de mai. de 2016.

Data de recebimento: $13 / 05 / 2016$

Data de aceite: 09/08/2016 